\title{
Reaction of Sorghum Lines Genetically Modified for Reduced Lignin Content to Infection by Fusarium and Alternaria spp.
}

\author{
Deanna L. Funnell, United States Department of Agriculture-Agricultural Research Service (USDA-ARS), Wheat, \\ Sorghum and Forage Research, and Department of Plant Pathology, University of Nebraska, Lincoln 68583-0937; \\ and Jeffrey F. Pedersen, USDA-ARS, Wheat, Sorghum and Forage Research, and Department of Agronomy, Uni- \\ versity of Nebraska, Lincoln
}

\begin{abstract}
Funnell, D. L., and Pedersen, J. F. 2006. Reaction of sorghum lines genetically modified for reduced lignin content to infection by Fusarium and Alternaria spp. Plant Dis. 90:331-338.

Two genes conferring the brown midrib (bmr) trait had been backcrossed into six elite sorghum lines, resulting in reduced lignin in the $b m r$ lines when compared with the wild-type parent. Seed and leaf tissue from field-grown plants, planted at two locations, were screened for Alternaria spp. and Fusarium spp. on semi-selective media. The results suggest that bmr lines do not have increased susceptibility to colonization by Alternaria spp. However, significantly fewer colonies of Fusarium spp., including Fusarium moniliforme, were recovered from seed of reduced lignin lines from two genetic backgrounds. That the bmr trait in some genetic backgrounds might enable increased resistance to colonization by $F$. moniliforme was further supported by greenhouse experiments in which peduncles of developing heads were inoculated with $F$. moniliforme. Mean lesion measurements on $b m r$ lines were significantly lower than those resulting from inoculations on wild-type lines. Analysis of near-isogenic lines revealed that mean lesion lengths on $b m r$ lines were significantly less than those produced on their wild-type counterparts in four of the six genetic backgrounds. These results suggest that reduced lignin lines exhibit, in some cases, increased resistance to Fusarium spp., including F. moniliforme.
\end{abstract}

Additional keywords: bmr-6, bmr-12, Fusarium verticillioides, grain mold

The brown midrib (bmr) trait of grasses has been utilized in breeding programs of forage crops to increase digestibility for ruminant animals. First recognized as a spontaneous mutant of maize in 1924 (29), bmr is characterized by reddish-brown pigmentation, most noticeable in the midrib of young plants, and is associated with reduced lignin content (15). The bmr trait has been induced in sorghum using chemical mutagenesis (15). Genetic and molecular studies of bmr maize and sorghum have shown that the bmr phenotype results from impaired function of enzymes involved in the lignin biosynthetic pathway $(58,73)$.

Much focus has been placed on lignin and nutrient availability in forage crops $(14,51)$; however, reduced lignin content

Corresponding author: D. L. Funnell

E-mail: dfunnell@unlserve.unl.edu

Mention of trade names or commercial products in this article is solely for the purpose of providing specific information and does not imply recommendation or endorsement by the United States Department of Agriculture.

Accepted for publication 21 October 2005.

DOI: 10.1094/PD-90-0331

This article is in the public domain and not copyrightable. It may be freely reprinted with customary crediting of the source. The American Phytopathological Society, 2006. also may improve efficiency of ethanol production (33) or facilitate decomposition of residue in conservation tillage management systems (71). However, lignin is essential to integrity and fitness of plants, especially of those in natural (nonagronomic) systems (56). Reduced lignin can impact crop yields by alteration or impairment of development $(72,78)$ or by increased lodging making harvesting and management difficult (78). Additionally, lignin likely is involved in defense against pathogens and insects (75), first, by providing a physical barrier against initial ingress and infestation $(9,11)$ and, second, as an induced response. The induced response may be in the form of rapid deposition of lignin or lignin-like materials which may prevent further growth and confine the invading pest $(4,8,24,41,65,68)$. With fungal pathogens, a correlation between resistance to an avirulent pathovar and accumulation of lignin or lignin-like products at the infection site has been observed $(18,25)$.

Precursors involved in the lignin biosynthetic pathway (74) also may play a role in disease defense (47). Metabolites of the lignin pathway have been shown to inhibit growth of pathogenic fungi or inhibit production of virulence factors, such as toxins, in vitro $(6,17,23,39)$. Accumulation of lignin precursors following attempted infection by nonpathogens can occur concur- rently with the induction of systemic resistance (66). Accumulation of ferulic acid, $p$ coumaric acid, and sinapic acid has been correlated with resistance to Fusarium spp. $(39,67)$. On the other hand, cinnamic acid derivatives (70) or $p$-coumaric acid (34) can induce virulence during host interactions with Agrobacterium tumefaciens. Perturbations in the lignin biosynthetic pathway could modify interactions between plants and potential pathogens or insect pests on many levels: from the structural integrity of the whole plant to responses at the cellular level and at the interface between the plant and potential pest or beneficial microorganism. Nonetheless, increase of carbon accessibility has been balanced with possible losses due to reduced fitness $(33,52)$.

The bmr-6 and bmr-12 genes were backcrossed successfully into six elite grain sorghum lines (Wheatland, Redlan, RTx430, BTx623, BTx630, and ВTx631; 53). Because grain sorghum previously was bred for reduced height (69), problems with lodging have been eliminated in these $\mathrm{bmr}$ lines (53). However, average grain yields in lines with $b m r-6$ or $b m r-12$ were significantly lower (83.5 and $80.5 \%$, respectively) than in wild-type lines (53). Residue dry weight produced by $b m r-12$ lines was significantly greater than that of wild-type and $b m r-6$ lines (by 10.5 and $23.1 \%$, respectively), whereas residue dry weights of $b m r-6$ lines were significantly less than those of wild-type lines $(89.8 \%$; 53). Lignin content was significantly less than wild-type for $b m r-6$ and $b m r-12$ lines, with lines containing $b m r-12$ having the greatest reduction (53).

Two fungal genera that are prevalent in field-grown sorghum, even in asymptomatic tissue, are Alternaria and Fusarium $(30,57,64,77)$. Under less than optimal conditions, such as plant wounding, colonization by microorganisms, or weather favorable for pathogenesis, apparent nonpathogenic growth by Fusarium or Alternaria spp. could become damaging $(57,77)$. Both genera contain species that produce secondary metabolites toxic to humans and livestock $(16,50,77)$. In particular, members of the Fusarium moniliforme complex can produce fumonisins that can cause inefficient growth and reduced production in livestock or immunosuppression or other serious and poten- 
tially deadly diseases in livestock and humans $(7,13,37)$. Because sorghum is utilized as both livestock feed and human food $(21,63)$, a thorough assessment of the ability of newly developed cultivars to resist colonization by Alternaria spp. and by $F$. moniliforme and other Fusarium spp., even without obvious detriment to the crop, seems prudent.

The first objective of this study was to determine levels of infection by Fusarium and Alternaria spp. in seed and leaf tissues from field-grown sorghum lines containing $b m r-6$ and $b m r-12$ compared with the same tissues from near-isogenic wild-type lines. The second objective was to compare nearisogenic $b m r-6, b m r-12$, and wild-type lines for lesion formation following inoculation with an $F$. moniliforme isolate pathogenic to sorghum.

\section{MATERIALS AND METHODS}

Plant lines and fungal isolates. The genes $b m r-6$ and $b m r-12$ were backcrossed into six elite sorghum lines: RTx430, BTх623, ВTх630, BTx631, Redlan, and Wheatland (55). In all, 18 lines (bmr-6, $b m r-12$, and the wild-type in each genetic background) were included in this study. $F$. moniliforme (M-3790), originally isolated from sorghum stalk, was obtained from the Fusarium Research Center, Pennsylvania State University, University Park.

Cultivation of $b m r$ lines in the field and collection of plant materials. Each parental line and corresponding nearisolines containing $b m r-6$ or $b m r-12$ were grown during 2002 in two-row plots $7.6 \mathrm{~m}$ long spaced $76 \mathrm{~cm}$ apart. Each plot was replicated four times at University of $\mathrm{Ne}$ braska Field Laboratories at Lincoln and Ithaca, NE. Fields at Ithaca were irrigated with $5 \mathrm{~cm}$ of water using an overhead sprinkler once per month in the months of June, July, and August. Fields at Lincoln were not irrigated. Nitrogen fertilizer was applied prior to planting at both locations at $157 \mathrm{~kg} \mathrm{ha}^{-1}$. At the Lincoln location, propachlor (2-chloro- $N$-[1-methylethyl]- $N$ phenylacetamide) and atrazine (6-chloro$n$-ethyl- $N$ '-[1-methylethyl]-1,3,5-trazine2,4-diamine) were applied at 3.36 and

Table 1. Mean daily high temperature (Mean temp) and precipitation by month at Lincoln and Ithaca, $\mathrm{NE}$ in $2002^{\mathrm{x}}$

\begin{tabular}{|c|c|c|c|c|}
\hline \multirow[b]{2}{*}{ Month } & \multicolumn{2}{|c|}{ Lincoln $^{y}$} & \multicolumn{2}{|c|}{ Ithaca $^{z}$} \\
\hline & Mean temp $\left({ }^{\circ} \mathrm{C}\right)$ & Precipitation $(\mathrm{cm})$ & Mean temp $\left({ }^{\circ} \mathrm{C}\right)$ & Precipitation $(\mathrm{cm})$ \\
\hline May & $24.2 \pm 5.1$ & 6.60 & $26.2 \pm 7.4$ & 3.60 \\
\hline June & $31.9 \pm 3.6$ & 0.20 & $31.8 \pm 3.8$ & 2.03 \\
\hline July & $34.2 \pm 3.9$ & 1.40 & $34.1 \pm 3.8$ & 3.15 \\
\hline August & $31.4 \pm 3.9$ & 21.06 & $30.2 \pm 2.2$ & 16.7 \\
\hline September & $32.7 \pm 2.1$ & 0.00 & $26.5 \pm 5.9$ & 3.58 \\
\hline October & N/A & N/A & $19.7 \pm 5.4$ & 6.76 \\
\hline
\end{tabular}

${ }^{\mathrm{x}}$ Mean daily high temperature, followed by standard deviations, and total rainfall, by month, from planting date (in May) to harvest date (in September or October). N/A indicates not applicable.

y Planting date at Lincoln was 20 May 2002 and harvest dates for seed and leaf tissue were 4 and 6 September 2002, respectively.

${ }^{\mathrm{z}}$ Planting date at Ithaca was 22 May 2002 and harvest date for seed and leaf tissue was 9 October 2002.

$1.1 \mathrm{~kg} \mathrm{ha}^{-1}$, respectively, immediately after planting for weed control. At the Ithaca location, atrazine was applied at $2.2 \mathrm{~kg} \mathrm{ha}^{-1}$ immediately after planting, followed by an quinolinecarboxylic acid) and atrazine at 0.37 and $1.1 \mathrm{~kg} \mathrm{ha}^{-1}$, respectively, approximately 14 days post emergence. Bentazon (2-[1-methylethyl]-1H-2,1,3-benzothiadiazin $4[3 \mathrm{H}]$-one-2,2-dioxide) was added to the post-emergence application at $0.28 \mathrm{~kg} \mathrm{ha}^{-1}$ for velvetleaf (Abutilon theophrasti (Medik)) control. Planting dates, harvest dates, mean temperatures, and precipitation at each location are listed in 1. Upon maturity, seed were colthe third fully expanded leaf from the top of five randomly chosen plants was collected. Plant tissues were stored at $4^{\circ} \mathrm{C}$.

grown plants. Seed were surface sterilized in $95 \%$ ethanol followed by $1 \%$ sodium hypochlorite with $0.01 \%$ Tween 20 (81) and plated onto semi-selective media using surface sterilized forceps. For the prelimiscreen, 5 seed from each replicate location) were selected on DCPA medium (2) that contains dichloran (Ultra Scientific, North Kingstown, RI) and chloram(Sigma-Aldrich, St. Louis). perature for 2 to 3 days until the appearance of aerial mycelia. Wild-type, $b m r-6$, and bmr12 lines from backgrounds BTx630, BTx631, BTx623, and Wheatland mately 25 seed further by plating approxilocation onto DCPA. Approximately 25 seed collected from each replicate plot and each location of Wheatland background 25 seed from each replicate plot from screened on PCNB medic tains the fungicide pentachloronitrobenzene (Terrachlor; Uniroyal Co., Middlebury, CT) and streptomycin (Sigmato 10 days until the appearance of aerial mycelia.

332 Plant Disease /Vol. 90 No. 3
For leaf tissue, three disks from each leaf collected (15 leaf disks per replicate plot) were cut with a \#6 cork borer, giving approximately $1 \mathrm{~cm}^{2}$ of tissue per sample. Leaf surfaces and cut edges of disks were sterilized by incubating in $1 \%$ sodium hypochlorite with gentle agitation for 10 min. Following decantation, the disks were rinsed three times with sterile, deinoized water. Leaf disks then were transferred aseptically onto DCPA medium. Plates were incubated at room temperature for 2 to 3 days, until aerial mycelium grew from disks.

Mycelia that grew from seed or leaf disks and onto the medium were transferred to half-strength potato dextrose agar (PDA; EM Scientific, Gibbstown, NJ). Isolates then were transferred from halfstrength PDA to water agar plates, covered with $0.5 \mathrm{~cm}^{2}$ of sterile filter paper, and allowed to grow 5 days (49). Fusarium spp. were identified by colony morphology on PDA and by morphology of spore and conidiophore structures on water agar $(31,46)$. Isolates that had characteristics and structures consistent with $F$. verticillioides were identified as belonging to $F$. moniliforme sensu lato $(36,59)$. Fusarium spp. other than those morphologically similar to $F$. verticillioides also were obtained from sorghum tissues and identified to species by morphological characteristics when possible. Other individual Fusarium spp. occurred with less frequency than those in the $F$. moniliforme sensu lato complex. To aid in statistical analysis, these other Fusarium spp. were grouped as a single class.

Controlled greenhouse assays. Seed from parental lines and $b m r-6$ and $b m r-12$ near-isolines were sown into a standard potting mixture in $13-\mathrm{cm}$ pots. After plants reached the three- to four-leaf stage, they were fertilized two times per week. At 1 to 1.5 months, plants were transplanted into $25-\mathrm{cm}$ pots and fertilized once every 2 weeks until heads developed. To wound inoculate plants, sterile toothpicks were incubated in a culture of $F$. moniliforme isolate M-3790 grown in $5 \mathrm{ml}$ of fullstrength potato dextrose broth (PDB) in a $50-\mathrm{ml}$ tube at $20^{\circ} \mathrm{C}$ for 10 days (27). Two weeks following anthesis, the toothpicks were used to inoculate peduncles of flowering heads from eight plants for each line (27). Eighteen days following inoculation, the peduncles were split longitudinally (27). Up to two measurements were made on each split peduncle: the length of the discoloration that spanned the radius of the peduncle (measurement 1) and the total length, which included a broken discontinuous discoloration, if present (measurement 2). To account for the response of plants to wounding, four plants of each line were inoculated with toothpicks incubated in sterile PDB alongside the $F$. moniliforme cultures. The resulting discoloration was measured as described above 
(measurements 1 and 2). The assay as described was conducted a total of three times.

Statistical analyses. Assessments of colonization by fungi in field-grown seed and leaf tissue and mean lesion lengths following inoculation with pathogens in greenhouse assays were analyzed using Proc MIXED (SAS, Cary, NC). The field experimental design was a split plot with whole plots arranged in a randomized complete block with four replications. Whole plots were lines and subplots were $b m r$ genes. Line, bmr gene, and location (due to irrigation treatments) were considered fixed and replication was considered random in the model. The greenhouse experimental design was a randomized complete block with three replications (assays). Line and $b m r$ gene were considered fixed and assay was considered random in the model. Appropriate error degrees of freedom were calculated in both field and greenhouse experiments by specifying the KENWARDROGER option in the model. Differences were considered significant when $P \leq 0.05$. Least squares means and standard errors are reported.

Preliminary analyses of data from the field experiment indicated that location effects and interactions were significant; therefore, data also were analyzed by location using an appropriately adjusted model to aid in data interpretation. For greenhouse bioassays, significant three-way interactions among inoculant $(F$. moniliforme versus sterile broth), gene, and genetic background were detected. Therefore, data also were analyzed by inoculum treatment to aid in data interpretation.

\section{RESULTS}

Isolation of fungi from seed and leaf tissues. Wild-type, $b m r-6$, and $b m r-12$ near-isogenic lines were grown in the field at Lincoln and Ithaca, NE. Collected seed were screened on DCPA and PCNB and leaf tissues were screened on DCPA.

Fungi isolated from seed of bmr lines by selection on DCPA medium. The seed from $\mathrm{bmr}$ and wild-type lines first were screened by plating 20 seed ( 5 seed/plot) from each line grown at each location onto DCPA medium. Mean numbers of total fungal colonies, Alternaria spp., F. moniliforme, and other Fusarium spp. isolated per seed collected from $b m r-6, b m r-12$, and wildtype plants were compared. Statistical analysis indicated no significant differences due to $b m r$ genes for these measurements when data were pooled across locations. However, location interactions with $b m r$ genotype were significant for mean numbers of Alternaria colonies isolated $(P=0.004)$. Upon analysis of data from each location for this measurement, there were significantly higher numbers of Alternaria colonies detected from seed of wild-type lines than from $b m r$ lines from plants grown at the irrigated location (Ithaca; $P<0.0001$; Table 2). There was no indication that this result was due to genetic background interacting with $\mathrm{bmr}$ genotypes $(P=0.653)$. No other measurements (numbers of total colonies, $F$. moniliforme isolates, or other Fusarium spp.) at either location were significantly different when comparing wild-type with $b m r$ genotypes (Table 2) in this preliminary screening using five seed per plot.

Fungal isolations were repeated with greater numbers of seed (approximately 25 per plot) from the lines Wheatland, BTx630, BTx631, and BTx623 plated onto DCPA in order to more precisely assess the effects of $b m r-6$ or $b m r-12$ in nearisogenic lines (Table 3). When analyzing data pooled across locations, significant differences among genotypes (wild-type, $b m r-6$, or $b m r-12$ ) were detected for mean numbers of colonies isolated per seed $(P=$ 0.017). However, there were $b m r$ gene interactions with location $(P=0.017)$ and genetic background $(P=0.003)$. Mean numbers of fungal isolates and Alternaria spp., F. moniliforme, or other Fusarium spp. isolated per seed for each genotype, by parental background, for plants grown at Lincoln and Ithaca are shown in Table 3. For the four genetic backgrounds tested at both locations, mean numbers of total fungal colonies, Alternaria colonies, $F$. moniliforme, or other Fusarium spp. per seed obtained from seed of $b m r-12$ lines were not greater than those from wild-type lines, except when considering total numbers of colonies per seed of $b m r-12$ BTx623 grown at Ithaca $(P=0.013$; Table $3)$. In the Wheatland background, significant differences between the $b m r$ genotypes were more apparent, especially for seed collected from plants grown at Ithaca (Table 3). Wheatland bmr-6 plant lines grown at Lincoln had greater mean numbers of colonies isolated per seed compared with seed from wild-type plants for measurements of total fungal colonies $(P=$ $0.025)$ and of Fusarium spp. other than $F$. moniliforme $(P=0.001$; Table 3$)$. For $b m r$ 6 Wheatland plants grown at Ithaca, mean numbers of total fungal colonies $(P=$ $0.013)$ and $F$. moniliforme isolations $(P=$ $0.002)$ per seed were significantly greater than those isolated from seed of wild-type plants (Table 3). All Wheatland plants, regardless of $b m r$ genotype, had significantly greater numbers of $F$. moniliforme isolates than cultivars BTх630, ВТх631, and BTx623 on seed obtained from plants grown at Ithaca $(P=0.0001,0.0001$, and 0.0003 , respectively). This suggests that Wheatland is inherently more susceptible to colonization by $F$. moniliforme than the other three cultivars under growth conditions present at Ithaca in 2002.

Fungi isolated from seed of bmr lines by selection on PCNB medium. Alternaria spp. were prevalent when screening grain from plants of $b m r$ and wild-type lines grown at Lincoln and Ithaca (Table 2). Therefore, seed from a subset of plots also were plated and fungal colonies selected on another semi-selective medium for Fusarium spp., PCNB $(45,60)$.

Seed from lines with the genetic backgrounds of Wheatland and RTx430 obtained from plants grown at Lincoln, and genetic background of RTx430 from plants grown at Ithaca, were plated onto PCNB. Seed collected from the same plots also were plated on DCPA (Tables 2 and 3). For all measurements, when considering both locations together, effects of media were significant $(P=0.002$ for mean numbers of $F$. moniliforme per seed, $P<0.0001$ for other measurements). When seed were

Table 2. Initial screen of seed collected from field-grown plants and plated onto dichloran chloramphenicol medium: mean numbers of colonies, Alternaria spp., Fusarium moniliforme, and other Fusarium spp. per seed ${ }^{\mathrm{x}}$

\begin{tabular}{|c|c|c|c|c|c|}
\hline Location, genotypey & No. of seed & No. of colonies & No. of Alternaria spp. & No. of $F$. moniliforme & No. of other Fusarium spp. \\
\hline \multicolumn{6}{|l|}{ Lincoln, NE } \\
\hline Wild-type & 120 & $0.908 \pm 0.046$ & $0.725 \pm 0.066$ & $0.008 \pm 0.001$ & $0.125 \pm 0.035$ \\
\hline$b m r-6$ & 120 & $0.908 \pm 0.046$ & $0.775 \pm 0.066$ & $0.000 \pm 0.001^{z}$ & $0.117 \pm 0.035$ \\
\hline$b m r-12$ & 120 & $0.867 \pm 0.046$ & $0.742 \pm 0.066$ & $0.008 \pm 0.001$ & $0.058 \pm 0.035$ \\
\hline \multicolumn{6}{|l|}{ Ithaca, NE } \\
\hline Wild-type & 120 & $1.067 \pm 0.034$ & $0.808 \pm 0.051 \mathrm{a}$ & $0.067 \pm 0.022$ & $0.092 \pm 0.035$ \\
\hline$b m r-6$ & 120 & $0.958 \pm 0.034$ & $0.558 \pm 0.034 \mathrm{c}$ & $0.025 \pm 0.022$ & $0.117 \pm 0.035$ \\
\hline$b m r-12$ & 120 & $1.000 \pm 0.034$ & $0.667 \pm 0.034 b$ & $0.083 \pm 0.022$ & $0.108 \pm 0.035$ \\
\hline
\end{tabular}


plated onto PCNB, significant differences in $b m r$ genotypes were noted for numbers of total fungal colonies, numbers of $F$. moniliforme isolated, and numbers of other Fusarium spp. isolated from seed grown at both locations $(P=0.001,0.004$, and 0.0001 , respectively). When analyzed by location (Table 4), mean numbers of isolates from $b m r-12$ seed were significantly less than those obtained from wild-type seed for numbers of colonies isolated and for Fusarium spp. other than F. moniliforme at both Lincoln $(P=0.0003$ and 0.0001 , respectively) and Ithaca $(P=$ 0.0001 and 0.002 , respectively) (Table 4). Also at Ithaca, mean numbers of $F$. moniliforme isolations were significantly less for seed from $b m r-12$ plants than for isolations from wild-type plants $(P=0.008$; Table 4$)$. Seed obtained from bmr-6 lines had significantly fewer isolations than wild-type seed for the measurements of total fungal colonies and mean numbers of Fusarium spp. other than $F$. moniliforme isolated per seed from plants grown at Ithaca $(P=$ 0.004 and 0.008, respectively; Table 4). When seed from the same subset of lines was plated onto DCPA, there were no significant differences in mean numbers of total fungal colonies, Alternaria colonies, F. moniliforme, and other Fusarium spp. (Tables 2 and 3). This suggests that DCPA medium was less sensitive for detecting differences between fungal colonization of these lines grown under the environmental conditions in this study.

Fungi isolated from leaf tissue of bmr lines by selection on DCPA medium. Because the bmr trait likely would impact nonreproductive parts of the plant (1), large numbers of leaf tissue samples were screened on DCPA medium (Table 5). When leaf disks (approximately $1 \mathrm{~cm}^{2}$ ) were plated onto DCPA medium, there were no significant differences between means of fungal isolation from $b m r$ lines and wild-type cultivars for all measurements when data were pooled across locations. When analyzed by location, mean numbers of $F$. moniliforme isolated from bmr-6 leaf disks obtained from plants

Table 3. Screen of field-grown seed from near-isogenic lines plated onto dichloran chloramphenicol medium: mean numbers of colonies, Alternaria spp., Fusarium moniliforme and other Fusarium spp. per seed ${ }^{\mathrm{x}}$

\begin{tabular}{|c|c|c|c|c|c|}
\hline Location, parent & Genotype $^{y}$ & No. of colonies & No. of Alternaria spp. & No. of $F$. moniliforme & No. of other Fusarium spp. \\
\hline \multicolumn{6}{|l|}{ Lincoln, NE } \\
\hline Wheatland & Wild-type (100) & $0.940 \pm 0.039 b$ & $0.890 \pm 0.063$ & $0.010 \pm 0.016$ & $0.000 \pm 0.020 b^{z}$ \\
\hline Wheatland & $b m r-6(100)$ & $1.070 \pm 0.039 \mathrm{a}$ & $0.890 \pm 0.063$ & $0.020 \pm 0.016$ & $0.100 \pm 0.020 \mathrm{a}$ \\
\hline Wheatland & $b m r-12(98)$ & $0.897 \pm 0.039 \mathrm{~b}$ & $0.876 \pm 0.063$ & $0.000 \pm 0.016$ & $0.010 \pm 0.020 \mathrm{~b}$ \\
\hline ВТх630 & Wild-type (96) & $0.958 \pm 0.039$ & $0.854 \pm 0.063$ & $0.042 \pm 0.016$ & $0.052 \pm 0.020 \mathrm{ab}$ \\
\hline ВТх630 & $b m r-6(96)$ & $1.000 \pm 0.039$ & $0.781 \pm 0.063$ & $0.052 \pm 0.016$ & $0.104 \pm 0.020 \mathrm{a}$ \\
\hline BTх630 & $b m r-12(95)$ & $1.020 \pm 0.039$ & $0.874 \pm 0.063$ & $0.042 \pm 0.016$ & $0.031 \pm 0.020 \mathrm{~b}$ \\
\hline ВТх631 & Wild-type (86) & $0.911 \pm 0.039$ & $0.634 \pm 0.063$ & $0.023 \pm 0.016$ & $0.046 \pm 0.020$ \\
\hline BTx631 & $b m r-6(89)$ & $0.946 \pm 0.039$ & $0.744 \pm 0.063$ & $0.031 \pm 0.016$ & $0.054 \pm 0.020$ \\
\hline BTx631 & $b m r-12(89)$ & $0.887 \pm 0.039$ & $0.711 \pm 0.063$ & $0.000 \pm 0.016$ & $0.011 \pm 0.020$ \\
\hline BTx623 & Wild-type (100) & $0.900 \pm 0.039$ & $0.880 \pm 0.063$ & $0.010 \pm 0.016$ & $0.000 \pm 0.020$ \\
\hline BTх623 & $b m r-6(98)$ & $1.010 \pm 0.039$ & $0.887 \pm 0.063$ & $0.020 \pm 0.016$ & $0.041 \pm 0.020$ \\
\hline BТх623 & $b m r-12(100)$ & $0.970 \pm 0.039$ & $0.910 \pm 0.063$ & $0.030 \pm 0.016$ & $0.030 \pm 0.020$ \\
\hline \multicolumn{6}{|l|}{ Ithaca, NE } \\
\hline Wheatland & Wild-type (100) & $1.020 \pm 0.050 \mathrm{~b}$ & $0.680 \pm 0.063$ & $0.240 \pm 0.037 \mathrm{~b}$ & $0.070 \pm 0.038$ \\
\hline Wheatland & $b m r-6(100)$ & $1.190 \pm 0.050 \mathrm{a}$ & $0.520 \pm 0.063$ & $0.390 \pm 0.037 \mathrm{a}$ & $0.160 \pm 0.038$ \\
\hline Wheatland & $b m r-12(100)$ & $1.070 \pm 0.050 \mathrm{ab}$ & $0.790 \pm 0.063$ & $0.140 \pm 0.037 \mathrm{c}$ & $0.080 \pm 0.038$ \\
\hline ВТх630 & Wild-type (92) & $0.888 \pm 0.050$ & $0.702 \pm 0.063$ & $0.033 \pm 0.037$ & $0.115 \pm 0.038$ \\
\hline BTх630 & $b m r-6(96)$ & $0.969 \pm 0.050$ & $0.698 \pm 0.063$ & $0.052 \pm 0.037$ & $0.063 \pm 0.038$ \\
\hline ВТх630 & $b m r-12(95)$ & $1.043 \pm 0.050$ & $0.718 \pm 0.063$ & $0.063 \pm 0.037$ & $0.105 \pm 0.038$ \\
\hline BTx631 & Wild-type (92) & $0.933 \pm 0.050$ & $0.654 \pm 0.063$ & $0.075 \pm 0.037$ & $0.052 \pm 0.038$ \\
\hline ВТх631 & $b m r-6(86)$ & $0.936 \pm 0.050$ & $0.796 \pm 0.063$ & $0.025 \pm 0.037$ & $0.023 \pm 0.038$ \\
\hline BTx631 & bmr-12 (88) & $0.931 \pm 0.050$ & $0.723 \pm 0.063$ & $0.033 \pm 0.037$ & $0.058 \pm 0.038$ \\
\hline BTх623 & Wild-type (100) & $0.870 \pm 0.050 \mathrm{~b}$ & $0.710 \pm 0.063$ & $0.080 \pm 0.037$ & $0.080 \pm 0.038$ \\
\hline BTх623 & $b m r-6(100)$ & $0.740 \pm 0.050 \mathrm{~b}$ & $0.620 \pm 0.063$ & $0.040 \pm 0.037$ & $0.040 \pm 0.038$ \\
\hline BTx623 & $b m r-12(100)$ & $1.040 \pm 0.050 \mathrm{a}$ & $0.770 \pm 0.063$ & $0.080 \pm 0.037$ & $0.038 \pm 0.038$ \\
\hline
\end{tabular}

${ }^{\mathrm{x}}$ Comparisons are made between brown midrib $(\mathrm{bmr})$ genotypes within genetic backgrounds (parent) and for each location. Least square means and standard errors are reported. In some cases, there were significant differences between the three $b m r$ genotypes within a parental background at a location. These are denoted with letters. Means having different letters are significantly different $(P \leq 0.05)$. Sets of numbers lacking letters are not significantly different from one another within a parental background.

${ }^{\mathrm{y}}$ Approximately 25 seed per genotype per plot were plated. Total numbers of seed for each genotype are indicated in parentheses.

${ }^{\mathrm{z}} 0.000$ Indicates no isolates obtained from seed screened of indicated genotype.

Table 4. Seed, collected from Wheatland (Lincoln) and RTx430 (Lincoln and Ithaca) near-isogenic brown midrib (bmr) lines plated onto pentachloronitrobenzene medium: mean numbers of colonies, Alternaria spp., Fusarium moniliforme, and other Fusarium spp. per seed ${ }^{\mathrm{w}}$

\begin{tabular}{lccccc}
\hline Location, genotype & No. of seed tested & No. of colonies & No. of Alternaria spp. & No. of $\boldsymbol{F}$. moniliforme & No. of other $\boldsymbol{F u s a r i u m}$ spp. \\
\hline Lincoln, NE & & & & & \\
$\quad$ Wild-type & 105 & $0.581 \pm 0.082 \mathrm{a}$ & $0.000^{\mathrm{x}}$ & $0.076 \pm 0.036$ & $0.477 \pm 0.063 \mathrm{a}$ \\
bmr-6 & 97 & $0.513 \pm 0.082 \mathrm{a}$ & 0.000 & $0.129 \pm 0.036$ & $0.315 \pm 0.063 \mathrm{a}$ \\
bmr-12 & 95 & $0.022 \pm 0.082 \mathrm{~b}$ & 0.000 & $0.000 \pm 0.036^{\mathrm{y}}$ & $0.026 \pm 0.063 \mathrm{~b}$ \\
Ithaca, NE & 53 & $0.931 \pm 0.093 \mathrm{a}$ & $0.000^{\mathrm{x}}$ & $0.320 \pm 0.066 \mathrm{a}$ & $0.612 \pm 0.082 \mathrm{a}$ \\
Wild-type & 51 & $0.421 \pm 0.093 \mathrm{~b}$ & 0.000 & $0.171 \pm 0.066 \mathrm{ab}$ & $0.234 \pm 0.082 \mathrm{~b}$ \\
bmr-6 & 50 & $0.100 \pm 0.093 \mathrm{c}$ & 0.000 & $0.000 \pm 0.066 \mathrm{~b}^{\mathrm{z}}$ & $0.100 \pm 0.082 \mathrm{~b}$ \\
bmr-12 & &
\end{tabular}

${ }^{\mathrm{w}}$ Least square means and standard errors are reported. In some cases, there were significant differences between the three $b m r$ genotypes at a location. These are denoted with letters. Means having different letters are significantly different $(P \leq 0.05)$. Sets of numbers lacking letters are not significantly different from one another; 0.000 indicates no isolates obtained from the indicated seed.

${ }^{x}$ Unable to analyze due to infinite likelihood.

${ }^{\mathrm{y}}$ No F. moniliforme colonies were isolated from Wheatland or RTx430 bmr-12 seed grown at Lincoln in any experiment.

${ }^{\mathrm{z}}$ When RTx430 bmr-12 seed obtained from plants grown at Ithaca were plated onto dichloran chloramphenicol medium, the mean number of $F$. moniliforme obtained per seed was 0.100 . 
grown at Lincoln were significantly greater than those isolated from wild-type or $b m r-$ 12 plants $(P=0.016$; Table 4$)$. Analysis indicated that genetic background did not interact with $b m r$ genotype for this measurement in plants grown at Lincoln $(P=$ 0.996). When considering fungi isolated from leaf tissue for both locations, interactions between genetic background and $\mathrm{bmr}$ genotype were not significant for mean numbers of fungal colonies, Alternaria spp. isolated, F. moniliforme isolates, and other Fusarium spp. isolated per seed $(P=$ $0.071,0.620,0.711$, and 0.814 , respectively).

Fusarium spp. isolated from leaf and seed tissue. In addition to members of $F$. moniliforme sensu lato, the following Fusarium spp., as determined by colony appearance, spore morphology, and conidiophore structure, were isolated from seed collected at both Ithaca and Lincoln (in alphabetical order): F. equiseti (Corda) Sacc. sensu Gordon (20), F. graminearum Schwabe, $F$. oxysporum Schlechtend. Emend. W. C. Snyder \& H. N. Hans., F. proliferatum (T. Matsushima) Nirenberg (48), F. solani (Mart.) Appel \& Wollenweb. Emend. W. C. Snyder \& H. N. Hans., F. thapsinum Klittich, Leslie, Nelson et Marasas, sp. nov. (31). and other unidentified Fusarium spp. Fusarium spp. isolated from leaf tissue obtained from plants grown at Ithaca were (in alphabetical order): F. equiseti, F. graminearum, Fusarium lateritium Nees:Fr., F. proliferatum, $F$. solani, F. subglutinans (Wollenweb. \& Reinking) P. E. Nelson, T. A. Tousson, \& Marasas com. nov., and $F$. thapsinum. Fusarium spp. isolated from leaf tissue of plants grown at Lincoln were (in alphabetical order): $F$. acuminatum Ellis \& Everh. sensu Gordon (20), F. chlamydosporum Wollenweb. \& Reinking, $F$. equiseti, F. graminum Corda, F. lateritium, $F$. proliferatum, F. solani, $F$. subglutinans, and $F$. thapsinum.

Inoculation assays of $\mathrm{bmr}$ and wildtype lines with a pathogenic $F$. moniliforme isolate conducted in the greenhouse. Peduncles of developing heads on plants from each genotype in each genetic background were wound inoculated with toothpicks incubated in a broth culture of a sorghum isolate of $F$. moniliforme or with toothpicks incubated in sterile broth (see Materials and Methods; 27). Three assays were conducted and the results were combined using assays as blocks for analyses. Inoculum treatments $(F$. moniliforme versus sterile broth) and interactions were significant for both lesion measurements. Mean lesion lengths resulting on $F$. moniliforme-inoculated $b m r-6$ and $b m r-12$ plants were significantly less than those resulting when wild-type plants were inoculated (Fig. 1A) when either measurement was analyzed (bmr-6: measurement $1, P=$ 0.0003 , measurement $2, P<0.0001$; bmr-
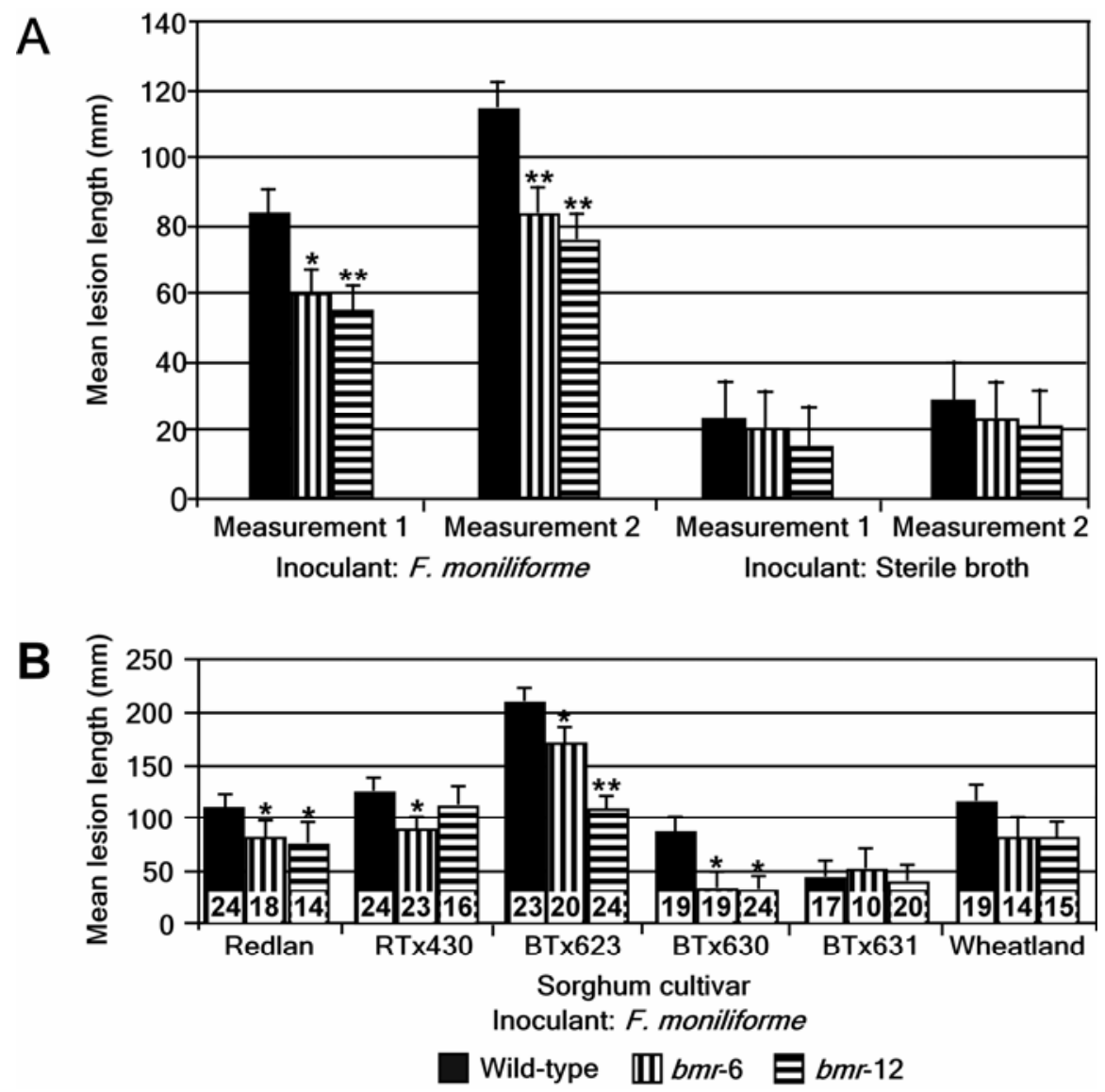

Fig. 1. Mean measurement lengths $(\mathrm{mm})$ resulting from wound inoculation of peduncles of developing heads of brown midrib $(\mathrm{bmr})$ lines and wild-type counterparts. An asterisk (*) indicates that mean measurement length is significantly less than that produced on wild-type at $P \leq 0.05$; ** indicates that mean measurement length is highly significantly less than that produced on wild-type at $P<0.0001$. A, Response of plants to inoculation with Fusarium moniliforme (left) or sterile broth (right) by bmr genotype. Mean lesions lengths $(\mathrm{mm})$ with positive standard errors of measurements 1 and $2 \mathrm{of} \mathrm{bmr}$ genotypes 18 days following inoculation. In all, 126 wild-type, $104 \mathrm{bmr}$-6, and $113 \mathrm{bmr}$-12 plants were inoculated with $F$. moniliforme while 66 wild-type, $57 \mathrm{bmr}$-6, and $52 \mathrm{bmr}$-12 plants were inoculated with sterile broth. B, Response (measurement 2 ) of plants to inoculation with $F$. moniliforme showing line-bmr gene interactions. Number of plants inoculated for each genotype is indicated on bars. Line is indicated on $X$ axis.

Table 5. Disks (approximately $1 \mathrm{~cm}^{2}$ ) removed from leaves collected from field grown plants and plated onto dichloran chloramphenicol medium: mean numbers of colonies, Alternaria spp., Fusarium moniliforme, and other Fusarium spp. per disk ${ }^{\mathrm{z}}$

\begin{tabular}{lccccc}
\hline Location, genotype & $\begin{array}{c}\text { No. of } \\
\text { leaf disks }\end{array}$ & No. of colonies & No. of Alternaria spp. & No. of $\boldsymbol{F}$. moniliforme & No. of other $\boldsymbol{F u s a r i u m}$ spp. \\
\hline $\begin{array}{l}\text { Lincoln, NE } \\
\text { Wild-type }\end{array}$ & 348 & $1.379 \pm 0.112$ & $0.612 \pm 0.070$ & $0.011 \pm 0.012 \mathrm{~b}$ & $0.124 \pm 0.044$ \\
bmr-6 & 334 & $1.710 \pm 0.112$ & $0.719 \pm 0.070$ & $0.047 \pm 0.012 \mathrm{a}$ & $0.087 \pm 0.044$ \\
bmr-12 & 345 & $1.550 \pm 0.112$ & $0.717 \pm 0.070$ & $0.012 \pm 0.012 \mathrm{~b}$ & $0.057 \pm 0.044$ \\
Ithaca, NE & & & & & \\
Wild-type & 359 & $1.369 \pm 0.107$ & $0.587 \pm 0.074$ & $0.008 \pm 0.009$ & $0.031 \pm 0.015$ \\
bmr-6 & 343 & $1.519 \pm 0.107$ & $0.671 \pm 0.074$ & $0.017 \pm 0.009$ & $0.045 \pm 0.015$ \\
bmr-12 & 371 & $1.391 \pm 0.107$ & $0.630 \pm 0.074$ & $0.017 \pm 0.009$ & $0.045 \pm 0.015$ \\
\hline
\end{tabular}

${ }^{\mathrm{z}}$ Least square means and standard errors are reported. Mean numbers of $F$. moniliforme per leaf disk isolated from leaves collected from plants of different brown midrib $(b m r)$ genotypes grown at Lincoln are significantly different. Means indicated with different letters are significantly different $(P \leq 0.05)$. Sets of numbers lacking letters are not significantly different from one another. 
12: measurements 1 and $2, P<0.0001$ ). Line-genotype effects were significant (measurements 1 and $2, P=0.001$ ) for lesions resulting from inoculation with $F$. moniliforme. Mean lesion lengths for measurement 2 of wild-type, $b m r-6$, and bmr-12 lines in each genetic background are shown in Figure 1B. For Redlan, RTx430, BTx623, and BTx630, significant differences between the wild-type line and one or both of the $b m r$ lines was noted (Fig. 1B). There were no differences detected due to the $b m r$ gene in Wheatland and BTx631 (Fig. 1B).

Considering only data from plants mock inoculated with sterile broth, no significant differences between the lengths of discolorations resulted when comparing $b m r$ genotypes with wild-type (bmr-6: measurement $1, P=0.532$, measurement $2, P=$ 0.397; bmr-12: measurement $1, P=0.219$, measurement $2, P=0.261$; Fig. 1A). Linegenotype interactions were not significant for measurements 1 or $2(P=0.257$ and 0.599 , respectively) when inoculated with sterile broth.

Significant main effects attributable to line in response to inoculation with $F$. moniliforme $(P<0.0001$ for both measurements) and sterile broth (measurement $1, P=0.003$, measurement $2, P<0.0001$ ) also were noticed. Following inoculation with $F$. moniliforme, all genotypes of BTx623 yielded significantly greater mean lesion measurements (measurement 1, $123.35 \pm 8.88 \mathrm{~mm}$; measurement 2, 164.09 \pm 9.58) than all other cultivars, while BTx630 and BTx631 had mean lesion lengths significantly less than the other cultivars (BTx630: measurement 1, 34.14 $\pm 9.14 \mathrm{~mm}$, measurement $2,50.03 \pm 9.77$ mm; BTx631: measurement 1, $31.61 \pm$ $9.86 \mathrm{~mm}$, measurement $2,43.70 \pm 10.70$ $\mathrm{mm}$; (Fig. 1B). BTx623 also had significantly greater mean measurements following inoculation with sterile broth compared with all other cultivars for measurement 2 $(53.89 \pm 11.36 \mathrm{~mm})$ and all cultivars but Wheatland for measurement 1 (38.13 \pm $11.85 \mathrm{~mm}$ ).

\section{DISCUSSION}

The purpose of this study was to ascertain whether the bmr lines developed to decrease lignin content of sorghum in six genetic backgrounds (55) have altered susceptibility to members of two genera of commonly found fungal pathogens or colonists. It was concluded that these $\mathrm{bmr}$ lines may have tolerance to Alternaria spp. and Fusarium spp., including $F$. moniliforme, equal to or possibly greater than their wild-type counterparts.

Yield determinations reported from field-grown plants had shown that yields per hectare were significantly less for $b m r$ lines than for their wild-type counterparts (53) and test weight $\left(\mathrm{kg} \mathrm{m}^{-3}\right)$, a measurement of grain density, was significantly less for lines containing $b m r-6$ than for lines containing $b m r-12$ or wild-type lines (53). Reduced yield and test weight may be explained, at least in part, by increased colonization by fungi $(14,22)$ that could impair plant growth and development or product quality. Therefore, the $b m r$ and wild-type lines were tested for colonization by two fungal genera prevalent in sorghum grain grown in Nebraska $(57,64)$. Screening of field-grown grain from six genetic backgrounds on DCPA semiselective medium indicated that $b m r$ lines were not colonized at a significantly greater degree with Alternaria and Fusarium spp. than wild-type lines, suggesting that the reduced lignin lines were not more susceptible to these fungi. Thus, fungal colonization by Alternaria and Fusarium spp. may not be contributing to the previously observed yield reduction. However, we were surprised to find that, when seed from field-grown plants were plated onto PCNB (45,60), F. moniliforme and other Fusarium spp. were recovered at a significantly lower rate in $b m r$ lines than in the wild-type lines (Table 4). This suggested that the bmr lines may be more resistant to these potentially pathogenic and mycotoxigenic fungi than their near-isogenic wild-type counterparts. Further support for this contention was provided when inoculations of the same lines with an F. moniliforme isolate pathogenic on sorghum (27) resulted in significantly smaller mean lesion lengths for $b m r$ lines than for wildtype cultivars (Fig. 1A).

When leaf tissue collected from fieldgrown $b m r$ lines and their wild-type counterparts was screened on the semi-selective medium DCPA, there were significantly greater numbers of $F$. moniliforme isolations recovered from $b m r-6$ lines grown at Lincoln when compared with $b m r-12$ and wild-type lines (Table 5). This suggests that reduction of lignin in leaves due to the presence of the $b m r-6$ gene may result in increased susceptibility to this pathogen in some environments. However, analysis of fungal colonization of leaf tissues from $b m r$ lines suggests that $b m r-12$ lines were not more susceptible to colonization by Alternaria and Fusarium spp., including $F$. moniliforme, than were wild-type lines.

A previous study has shown that there were significant differences in the presence of different fungi, including Alternaria spp. and $F$. moniliforme, when comparing visibly damaged sorghum grain with healthy-appearing grain (57). In a study of wheat, barley, and oat grain, "acceptable" grains were colonized primarily with an Alternaria spp., whereas Fusarium spp. were isolated to a greater extent from grains classified as reduced in quality (32). An inverse relationship between $F$. graminearum and Alternaria alternata (Fr.) Keissl. also was observed in fungal isolations from wheat seedlings, perhaps due in part to toxin production by $F$. graminearum (19). In the present study,
Alternaria spp. were isolated primarily when DCPA medium was used to screen seed samples from field-grown plants (Tables 2 and 3). However, when screening seed from the lines Wheatland and RTx430 on PCNB, no isolates of Alternaria spp. were obtained and statistical analysis indicated that there were significant differences in recovery of members of this genus on the two media (Tables 2, 3, and 4). Media also were significant when considering numbers of $F$. moniliforme isolations per seed on PCNB or DCPA $(P=0.0020)$ and, with some genotypes, it was possible to recover more $F$. moniliforme or other Fusarium spp. on PCNB medium than on DCPA (Tables 2, 3, and 4; data not shown).

Screens of seed and leaf material from field-grown plants of $\mathrm{bmr}$ lines indicated that these lines may be more resistant to colonization by Alternaria and Fusarium spp., including $F$. moniliforme, under some environmental conditions. These observations were further supported by controlled greenhouse studies in which $F$. moniliforme-inoculated $b m r-6$ and $b m r-12$ plants had significantly smaller mean lesion lengths (Fig. 1A) than wild-type lines. This relationship continued when considering four lines: inoculation of $b m r-6$ plants of cvs. Redland, RTx430, BTx623, or BTx630, or of $b m r-12$ plants of Redlan, BTx623, or BTx630, resulted in significantly smaller mean lesion lengths when lines were compared with their wild-type counterparts (Fig. 1B). Some genetic backgrounds appeared to perform better than others across $b m r$ genotypes (Table 3; Fig. 1B). This suggests that differences in basal secondary metabolic activity in the lignin pathway or in pathways that interact with the lignin pathway within a genetic background may affect how the $b m r$ mutations modify the balance of metabolites when these genes are incorporated into different wild-type backgrounds (79). In a previous report on grain sorghum $\mathrm{bmr}$ lines, it was shown that line-gene interactions were apparent for all agronomic traits measured, including height, grain yield, test weight, and dry matter yields (53). Field screens of accessions have allowed assessment of traits that may be involved in resistance to grain mold $(26,40)$, some of which are associated with secondary metabolites (26,39,76). Multiple genes involved in conferring these traits, as well as possible uncharacterized modifying genes, may cause differential responses in diverse genetic backgrounds.

This study demonstrated that $b m r$ lines bred for the purpose of reducing lignin content and increased digestibility were not more susceptible to members of two fungal genera that may be pathogenic, reduce grain quality, or produce mycotoxins $(14,22,35)$. It might seem unclear as to how a trait such as $b m r$, that alters lignin content in stalks, stems, and leaves 
$(33,52,53)$, would affect composition of grain. However, it has been shown that lignins and lignin precursors are components of cereal grains $(5,10,12)$. Additionally, lignin precursors may be involved in germination and may protect the grain or germinating seedling from pathogen attack $(3,61,62)$. It may be possible for grain to be colonized by fungi from nonreproductive plant parts $(42,44,54)$; thus, a reduction of infection from these parts conceivably could affect infection of grain. Lignin pathway intermediates can reduce insect feeding, which may allow transmittance of fungal spores or may result in injuries leaving the plant vulnerable to fungal ingress $(28,38,43,80)$. Therefore, an accumulation of precursors in floral or nonreproductive parts ultimately may protect developing grain $(3,39,67)$.

\section{ACKNOWLEDGMENTS}

We thank J. Toy for conducting the field research, B. Tlamka for laboratory and greenhouse work, S. Link for maintaining plants in the greenhouse, J. Soper and A. Wagner for providing technical assistance, and R. French and D. C. Stenger for providing editorial comments.

\section{LITERATURE CITED}

1. Akin, D. E., Hanna, W. W., Snook, M. E., Himmelsbach, D. S., Barton, F. E., II, and Windham, W. R. 1986. Normal-12 and brown midrib-12 sorghum. II. Chemical variations and digestibility. Agron. J. 78:832-837.

2. Andrews, S., and Pitt, J. I. 1986. Selective medium for isolation of Fusarium species and Dematiaceous Hyphomycetes from cereals. Appl. Environ. Microbiol. 51:1235-1238.

3. Assabgui, R. A., Reid, L. M. Hamilton, R. I., and Arnason, J. T. 1993. Correlation of kernel (E)-ferulic acid content of maize with resistance to Fusarium graminearum. Phytopathology 83:949-953.

4. Baayen, R. P., Ouellette, G. B., and Rioux, D. 1996. Compartmentalization of decay in carnations resistant to Fusarium oxysporum f. sp. Dianthi. Phytopathology 86:1018-1031.

5. Beaugrand, J., Crônier, D., Thiebeau, P., Schreiber, L., Debiere, P., and Chabbert, B. 2004. Structure, chemical composition and sylanase degradation of external layers isolated from developing wheat grain. J. Agric. Food Chem. 52:7180-7117.

6. Beekrumn S., Govinden, R., Padayachee, T., and Odhav, B. 2003. Naturally occurring phenols: a detoxification strategy for fumonisin B $_{1}$. Food Addit. Contam. 20:490-493.

7. Bondy, G. S., and Pestka, J. J. 2000. Immunomodulation by fungal toxins. J. Toxicol. Environ. Health B Crit. Rev. 3:109-143.

8. Bonello, P., Pearce, R. B., Watt, F., and Grime, G. W. 1991. An induced papilla response in primary roots of Scots pine challenged in vitro with Cylindrocarpon destructans. Physiol. Mol. Plant Pathol. 39:213-228.

9. Bonello, P., Storer, A. J., Gordon, T. R., Wood, D. L., and Heller, W. 2003. Systemic effects of Heterbasidion annosum on ferulic acid glucoside and lignin of presymptomatic ponderosa pine phloem, and potential effects on barkbeetle-associated fungi. J. Chem. Ecol. 29:1167-1182.

10. Bonoli, M., Verardo, V., Marconi., E., and Caboni, M. F. 2004. Antioxidant phenols in barley (Hordeum vulgare L.) flour: comparative spectrophotometric study among extraction methods of free and bound phenolic compounds. J. Agric. Food Chem. 52:5195-5200.

11. Buendgen, M. R., Coors, J. G., Grobacher, A.
W., and Russell, W. A. 1990. European corn borer and cell wall composition of three maize populations. Crop Sci. 30:505-510.

12. Bunzel, M., Ralph, J., Lu, F., Hatfield, R. D., and Steinhard, H. 2004. Lignins and ferulateconiferyl alcohol cross-coupling products in cereal grains. J. Agric. Food Chem. 52:64966502.

13. Casteel, S. W., Turk, J. R., and Rottinghaus, G. E. 1994. Chronic effects of dietary fumonisin on the heart and pulmonary vasculature of swine. Fundam. Appl. Toxicol. 23:518-524.

14. Castor, L. L., and Frederiksen, R. A. 1980. Fusarium head blight occurrence and effects on sorghum yield and grain characteristics in Texas. Plant Dis. 64:1017-1019.

15. Cherney, J. H., Cherney, J. R., Akin, D. E., and Axtell, J. D. 1991. Potential of brown-midrib, low-lignin mutants for improving forage quality. Adv. Agron. 46:157-198.

16. D'Mello, J. P. F., Placinto, C. M., and Macdonald, A. M. C. 1999. Fusarium mycotoxins: a review of global implications for animal health, welfare and productivity. Anim. Feed Sci. Technol. 80:183-205

17. Dowd, P. F., Duvick, J. P., and Rood, T., 1997. Comparative toxicity of allelochemicals and their enzymatic oxidation products to maize fungal pathogens, emphasizing Fusarium graminearum. Nat. Toxins 5:180-185.

18. Dushnicky, L. G., Balance, G. M., Sumner, M. J., and MacGregor, A. W. 1998. The role of lignification as a resistance mechanism in wheat to a toxin-producing isolate of Pyrenophora tritici-repentis. Can. J. Plant Pathol. 20:35-47.

19. González, H. H. L., Martínez, E. J., Pacin A., and Resnik, S. L. 1999. Relationship between Fusarium graminearum and Alternaria alternate contamination and deoxynivalenol occurrence on Argentinean durum wheat. Mycopathologia 144:97-102.

20. Gordon, W. L. 1952. The occurrence of Fusarium species in Canada. II. Prevalence and taxonomy of Fusarium species in cereal seed. Can. J. Bot. 30:209-251.

21. Hancock, J. D. 2000. Value of sorghum and sorghum coproducts in diets for livestock. Pages 731-749 in: Sorghum: Origin, History, Technology, and Production. John Wiley and Sons, Inc., New York.

22. Hepperly, P. R., Feliciano, C., and Sotomayor, A. 1982. Chemical control of seedborne fungi of sorghum and their association with seed quality and germination in Puerto Rico. Plant Dis. 66:902-904

23. Hua, S.-S. T., Grosjean, O.-K., and Baker, J. L. 1999. Inhibition of aflatoxin biosynthesis by phenolic compounds. Lett. Appl. Microbiol. 29:289-291.

24. Hudgins, J. W., Christiansen, E., and Franceschi, V. R. 2004. Induction of anatomically based defense responses in stems of diverse conifers by methyl jasmonate: a phylogenetic approach. Tree Physiol. 24:251-264.

25. Jaeck, E., Dumas, G., Geoffroy, P., Favet, N., Inzé, D., Van Montagu, M., Fritig, B., and Legrand, M.1992. Regulation of enzymes involved in lignin biosynthesis: induction of $O$ methyltransferase mRNAs during the hypersensitive reaction of tobacco to Tobacco Mosaic Virus. Mol. Plant-Microbe Interact. 5:294300.

26. Jambunathan, R., Kherdekar, M. S., and Bandyopadhyay, R. 1990. Flavan-4-ols concentration in mold susceptible and moldresistant sorghum at different stages of grain development. J. Agric. Food Chem. 38:545548.

27. Jardine, D. J., and Leslie, J. F. 1992. Aggressiveness of Gibberella fujikuroi (Fusarium moniliforme) isolates to grain sorghum under greenhouse conditions. Phytopathology 76:897-900.
28. Jarvis, J. L., Clark, R. L., Guthrie, W. D Berry, E. C., and Russell, W. A. 1984. The relationship between second-generation European corn borers and stalk rot of fungi in maize hybrids. Maydica 29:247-263.

29. Jorgenson, L. R. 1931. Brown midrib in maize and its linkage relations. J. Am. Soc. Agron. 23:549-557.

30. Kini, K. R., Leth, V., and Mathur, S. B. 2002. Genetic variation in Fusarium moniliforme isolated from seeds of different host species from Burkina Faso based on random amplified polymorphic DNA analysis. J. Phytopathol. 150:209-212.

31. Klittich, C. J. R., Leslie, J. F., Nelson, P. E. and Marasas, W. F. O. 1997. Fusarium thapsinum (Gibberella thapsina): A new species in section Liseola from sorghum. Mycologia 89:643-652.

32. Kosiak, B., Torp, M., Skjerve, E., and Andersen, B. 2004. Alternaria and Fusarium in Norwegian grains of reduced quality-a matched pair study. Int. J. Food Microbiol. 93:51-62.

33. Lam, T. B. T., Iiyama, K., and Stone, B. A. 1996. Lignin and hydroxycinnamic acids in walls of brown midrib mutants of sorghum, pearl millet and maize stems. J. Sci. Food Agric. $71: 174-178$

34. Lee, Y.-W., Jin, S., Sim, W.-S., and Nester, E. W. 1996. The sensing of plant signal molecules by Agrobacterium: genetic evidence for direct recognition of phenolic inducers by the VirA protein. Gene 179:83-88.

35. Leslie, J. F. Plattner, R. D., Desjardins, A. E., and Klittich, C. J. R. 1992. Fumonisin B 1 production by strains from different mating populations of Gibberella fujikoroi (Fusarium Section Liseola). Phytopathology 82:341-345.

36. Leslie, J. F., Zeller, K. A., Lamprecht, S. C., Rheeder, J. P., and Marasas, W. F. O. 2005 Toxicity, pathogenicity, and genetic differentiation of five species of Fusarium from sorghum and millet. Phytopathology 95:275-283.

37. Marín, S., Magan, N., Ramos, A. J., and Sanchis, V. 2004. Fumonisin-producing strains of Fusarium: A review of their ecopphysiology. J. Food Prot. 67:1792-1805.

38. Marley, P. S., and Malgwi, A. M. 1999. Influence of headbugs (Eurystylus sp.) on sorghum grain mould in the Nigerian savanna. J. Agric. Sci. 132:71-75.

39. McKeehen, J. D., Busch, R. H., and Fulcher, R. G. 1999. Evaluation of wheat (Triticum aestivum L.) phenolic acids during grain development and their contribution to Fusarium resistance. J. Agric. Food Chem. 47:1476-1482.

40. Menkir, A., Ejeta, G., Butler, L., and Melakeberhan, A. 1996. Physical and chemical properties associated with resistance to grain mold in sorghum. Cereal Chem. 73:613-617.

41. Mitchell, H. J., Hall, S. A., Stratford, R., Hall, J. L., and Barber, M. S. 1999. Differential induction of cinnamyl alcohol dehydrogenase during defensive lignification in wheat (Triticum aestivum $\mathrm{L}$.): characterisation of the major inducible form. Planta 208:31-37.

42. Munkvold, G. P., and Carlton, W. M. 1997. Influence of inoculation method on systemic Fusarium moniliforme infection of maize plants grown from infected seeds. Plant Dis. 81:211-216.

43. Munkvold, G. P., and Desjardins, A. E. 1997. Fumonisins in maize. Plant Dis. 81:556-565.

44. Munkvold, G. P., McGee, D. C., and Carlton, W. M. 1997. Importance of different pathways for maize kernel infection by Fusarium moniliforme. Phytopathology 87:209-217.

45. Nash, S. M., and Snyder, W. C. 1962. Quantitative estimates by plate counts of propagules of the bean root rot Fusarium in field soils. Phytopathology 52:567-572.

46. Nelson, P. E., Tousson, T. A., and Marasas, W. F. O. 1983. Fusarium Species: An Illustrated 
Manual for Identification. The Pennsylvania State University Press, University Park.

47. Nicholson, R. L., and Hammerschmidt, R. 1992. Phenolic compounds and their role in disease resistance. Annu. Rev. Phytopathol. 30:369-389.

48. Nirenberg, H. 1976. Untersuchungen über die morphologische und biologishe Differenzierung in der Fusarium-Sektion Liseola. Mitt. Biol. Bundesanst. Land Forstwirtsch. BerlinDahlem. 169:1-117.

49. Nirenberg, H. I., and O'Donnell, K. 1998. New Fusarium species and combination within the Gibberella fujikoroi species complex. Mycologia 90:434-458.

50. Norred, W. P. 1993. Fumonisins-mycotoxins produced by Fusarium moniliforme. J. Toxicol. Environ. Health 38:309-328.

51. Oliver, A. L., Grant, R. J., Pedersen, J. F., and O'Rear, J. 2004. Comparison of brown midrib6 and -18 sorghum with conventional sorghum and corn silage in diets of lactating dairy cows. J. Dairy Sci. 87:637-644.

52. Oliver, A. L., Pedersen, J. F., Grant, R. J., Klopfenstein, T. J., and Jose, H. D. 2005. Comparative effects of the sorghum bmr-6 and bmr-12 genes I: forage sorghum yield and quality. Crop Sci. 45:2234-2239.

53. Oliver, A. L., Pedersen, J. F., Grant, R. J., Klopfenstein, T. J., and Jose, H. D. 2005 Comparative effects of the sorghum bmr-6 and $b m r$ 12 genes II: grain yield, stover yield and stover quality in grain sorghum. Crop Sci. 45:22402245.

54. Oren, L., Ezrati, S., Cohen, D., and Sharon, A. 2003. Early events in the Fusarium verticillioides-maize interaction characterized by using a green fluorescent protein-expressing transgenic isolate. Appl. Environ. Microbiol. 69:1695-1701

55. Pedersen, J. F., Funnell, D. L., Toy, J. J., Oliver, A. L., and Grant, R. J. Registration of twelve grain sorghum genetic stocks nearisogenic for the brown midrib genes $b m r-6$ and $b m r-12$. Crop Sci. In press.

56. Pedersen, J. F., Vogel, K. P., and Funnell, D. L. 2005. Impact of reduced lignin on plant fitness. Crop Sci. 45:812-819.

57. Pettit, R. E., and Taber, R. A. 1978. Fungi involved in the deterioration of grain sorghum. Texas Agric. Exp. Stn. 1375:32-41

58. Pillonel, C., Mulder, M. M., Boon, J. J., Forster, B., and Binder, A. 1991. Involvement of cinnamyl-alcohol dehydrogenase in the control of lignin formation in Sorghum bicolor L. Moench. Planta 185:538-544.

59. Puhalla, J. E. 1981. Genetic considerations of the genus Fusarium. Pages 291-305 in Fusarium: Diseases, Biology and Taxonomy. The Pennsylvania State University Press, University Park

60. Rabie, C. J., Lübben, A., Marais, G. J., and Jansen van Vuuren, H. 1997. Enumeration of fungi in barley. Int. J. Food Microbiol. 35:117127.

61. Rasmussen, J. A., and Einhellig, F. A. 1977. Synergistic inhibitory effects of $p$-coumarix and ferulic acids on germination and growth of grain sorghum. J. Chem. Ecol. 3:197-205.

62. Reddy, M. V. B., Arul, J., Angers, P., and Coutre, L. 1999. Chitosan treatment of wheat seeds induces resistance to Fusarium graminearum and improves seed quality. J. Agric. Food Chem. 47:1208-1216.

63. Rooney, L. W., and Waniska, R. D. 2000. Sorghum food and industrial utilization. Pages 689-739 in: Sorghum: Origin, History, Technology, and Production. John Wiley and Sons, Inc., New York.

64. Seitz, L. M., Mohr, H. E., Burroughs, R., and Glueck, J. A. 1983. Preharvest fungal invasion of sorghum grain. Cereal Chem. 60:127-130.

65. Siegrist, J., Jeblick, W., and Kauss, H. 1994. Defense response in infected and elicited cucumber (Cucumis sativus L.) hypocotyls segments exhibiting acquired resistance. Plant Physiol. 105:1365-1374.

66. Singh, U. P., Sarma, B. K., and Singh, D. P. 2003. Effect of plant growth-promoting rhizobacteria and culture filtrate of Sclerotium rolfsii on phenolic and salicylic acid contents in chickpea (Cicer arietinum). Curr. Microbiol. 46:131-140.

67. Siranidou, A., Kang, Z., and Buchenauer, H. 2002. Studies on symptom development, phenolic compounds and morphological defence responses in wheat cultivars differeing in resistance to Fusarium head blight. J. Phytopathol. 150:200-208.

68. Smit, F., and Dubery, I. A. 1997. Cell wall reinforcement in cotton hypocotyls in response to Verticillium dahliae elicitor. Phytochemistry 44:811-815.

69. Smith, C. W., and Frederiksen, R. A., eds. 2000. Sorghum: Origin, History, Technology and Production. John Wiley \& Sons, Inc., New York.
70. Spencer, P. A., and Towers, G. H. N. 1989. Virulence-inducing phenolic compounds detected by Agrobacterium tumefaciens. Pages 383-398 in: Plant Cell Wall Polymers: Biogenesis and Biodegradation. American Chemical Society, Washington, DC.

71. Tian, G., Brussard, L., and Kang, B. T. 1993. Biological effects of plant residues with contrasting chemical compositions under humid tropical conditions: effects on soil fauna. Soil Biol. Biochem. 25:731-737

72. Vermerris, W. Thompson, K. J., and McIntyre, L. M. 2002. The maize Brown midribl locus affects cell wall composition and plant development in a dose-dependent manner. Heredity $88: 450-457$

73. Vignols, F., Rigau, J., Torres, M. A., Capellades, M., and Puigdomènech, P. 1995. The brown midrib3 (bm3) mutation in maize occur in the gene encoding caffeic acid $O$ methyltransferase. Plant Cell 7:407-416.

74. Vogel, K. P., and Jung, H. J. G. 2001. Genetic modification of herbaceous plants for feed and fuel. Crit. Rev. Plant Sci. 20:15-49.

75. Walter, M. H. 1992. Regulation of lignification in defense. Pages 327-362 in: Genes Involved in Plant Defense. Springer-Verlag, Germany.

76. Waniska, R. D., Venkatesha, R. T., Chandrashekar, A., Krishnaveni, S., Bejosani, F. P., Jeong, J. Jayaraj, J., Muthukrishnan, S., and Liang, G. H. 2001. Antifungal proteins and other mechanisms in the control of sorghum stalk rot and grain mold. J. Agric. Food Chem. 49:4732-4742.

77. Webley, D. J., Jackson, K. L., Mullins, J. D., Hocking, A. D., and Pitt, J. I. 1997. Alternaria toxins in weather-damaged wheat and sorghum in the 1995-1996 Australian harvest. Aust. J. Agric. Res. 48:1249-1255.

78. Weller, R. F., Phipps, R. H., and Cooper, A. 1985. The effect of the brown midrib-3 gene on the maturity and yield of forage maize. Grass Forage Sci. 40:335-339.

79. Whetten, R., and Sederoff, R. 1995. Lignin biosynthesis. Plant Cell 7:1001-1013.

80. Woodhead, S., and Cooper-Driver, G. 1979 Phenolic acids and resistance to insect attack in Sorghum bicolor. Biochem. Syst. Ecol. 7:309-310.

81. Wozniak, C. A., and Partridge, J. E. 1988 Analysis of growth in sorghum callus cultures and association with a $27 \mathrm{kD}$ peptide. Plant Sci. 57:235-246. 